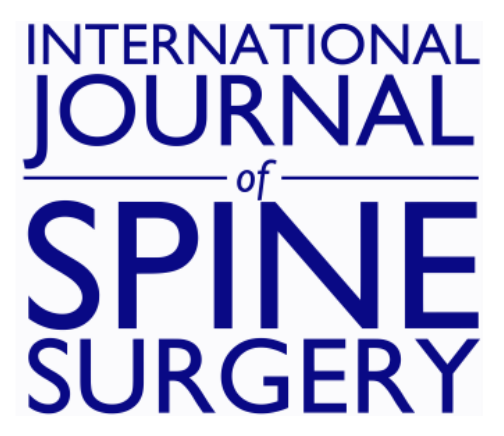

\title{
Early Fusion Rates After Direct Lateral Lumbar Interbody Fusion With Bone-Morphogenetic Protein
}

Hanci Zhang, Brian Dial and Christopher Brown

Int J Spine Surg 2021, 15 (3) 423-428

doi: https://doi.org/10.14444/8063

http://ijssurgery.com/content/15/3/423

This information is current as of April 26, 2023.

Email Alerts Receive free email-alerts when new articles cite this article. Sign up at:

http://ijssurgery.com/alerts 


\title{
Early Fusion Rates After Direct Lateral Lumbar Interbody Fusion With Bone-Morphogenetic Protein
}

\author{
HANCI ZHANG, MD, BRIAN DIAL, MD, CHRISTOPHER BROWN, MD \\ Department of Orthopaedic Surgery, Duke University Medical Center; Durham, North Carolina
}

\begin{abstract}
Background: Direct lateral (transpsoas) lumbar interbody fusion (LLIF) reportedly achieves union by 1 year postoperatively, but how soon fusion occurs after these minimally invasive procedures is unclear. This study investigated LLIF fusion progression at 6 months and 1 year in a large-scale cohort using bone morphogenetic protein (BMP) graft and examined risk factors associated with failed fusion.

Methods: Patients undergoing primary LLIF with a single surgical team from 2015 through 2016 with polyetheretherketone (PEEK) iimplants and BMP graft were identified. Retrospective chart review included demographics and medical history, construct length and location, and concurrent L5-S1 fusion. Inclusion criteria included minimum 1-year follow-up and postoperative lumbar computed tomography at 6 months and 1 year, which was independently assessed for bony union at each level.

Results: 166 patients underwent LLIF at a total of 312 levels. Seventy-nine patients (48\%) underwent 1-level fusion; 45 (27\%), 2 levels; and 42 (25\%), 3 or more levels. At 6 months, 160 (51\%) levels showed fusion. At 1 year, $70 \%$ of the remainder were fused, and total fusion rate was $85 \%$. Fusion rates from L1 through L4 were similar $(84 \%-87 \%)$. Nonunion was not significantly associated with construct length $(P=.19)$, concurrent anterior L5-S1 interbody fusion $(P=.50)$, age $(P=.70)$, BMI $(P=.15)$, or comorbidities such as diabetes $(P=.86)$ or thyroid disease $(P=.46)$.

Conclusions: This large retrospective cohort study corroborates prior 1-year LLIF fusion rate reports $(85 \%)$ independent of construct length or location or medical comorbidities. Significantly, half showed fusion by 6 months, earlier than previously described and validating the efficacy of LLIF.
\end{abstract}

Level of Evidence: 5.

Clinical Relevance: This study presents a large cohort of patients to support effective lumbar fusion after LLIF with BMP-2.

Lumbar Spine

Keywords: lumbar interbody fusion, direct lateral lumbar fusion, BMP-2, minimally invasive

\section{INTRODUCTION}

Direct lateral (transpsoas) lumbar interbody fusion (LLIF) is a minimally invasive surgical approach used to achieve spinal fusion in the lower thoracic and lumbar spine. First described in 2006, LLIF permits an extensive discectomy enabling a large surface area for intervertebral graft positioning while avoiding the great vessels that would be at risk during a traditional anterior lumbar interbody fusion (ALIF). ${ }^{1}$ Compared with posterior-based interbody fusion approaches, LLIF allows for insertion of a larger interbody cage. ${ }^{2}$ The larger cage geometry offers several advantages that may promote fusion: a larger surface area decreases the contact stresses at the implant-bone interface thereby lowering the risk of implant subsidence or migration, and a larger volume allows for greater amount of graft materials to be utilized.

Early studies of LLIF outcomes have suggested promising fusion rates. ${ }^{3-5}$ Initially, the approach was reserved for isolated single- or double-level fusions in select patients. ${ }^{4}$ As with any promising technique, however, its usage has rapidly expanded in the years since, especially as its utility in minimally invasive deformity correction is being recognized. ${ }^{6,7}$ As the scope of and indications for LLIF continue to grow, our current understanding of how effectively these more expansive surgeries achieve interbody fusion is yet to keep pace. This understanding is a critical foundation to direct postoperative rehabilitation guidelines, and one that has thus far depended on specific milestones reported in the literature, most commonly at 1 year. 

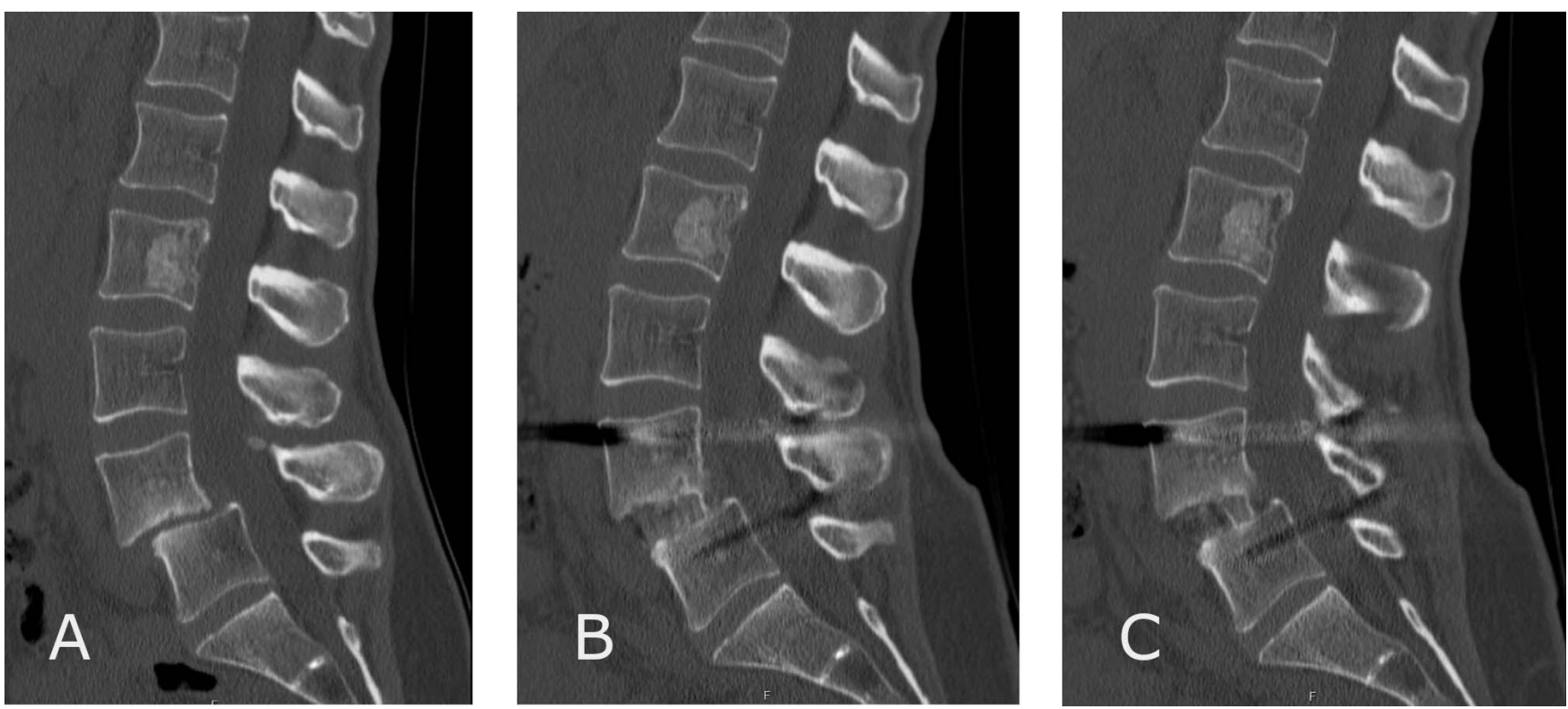

Figure. A 47-year-old female patient who presented with spondylolithesis of $L 4$ on $L 5$ in setting of bilateral pars defects (A) and underwent single-level lateral lumbar interbody fusion at L4-5. Six-month postoperative computed tomography scan showed continuous bony union across the interbody cage (B, C).

Clinically, however, it is recognized that fusion may occur sooner, although how soon it is achieved and at what frequency is yet unknown. This study sought to investigate the course of lumbar fusion after LLIF by (1) measuring fusion rates at 6 months and 12 months postoperatively in a largescale cohort and (2) assessing potential causes of pseudoarthrosis, including LLIF construct length.

\section{METHODS}

In this study, which was approved by the Institutional Review Board at the authors' institution, where all investigations were performed, a retrospective chart review was performed of all patients undergoing LLIF procedures by a single, fellowship-trained attending surgeon at the authors' institution during 2015-2016. Information collected from the chart review included patient demographics, medical history, construct length and location, and selected implants and grafts. Inclusion criteria included primary LLIF procedures with minimum 1-year follow-up and dedicated lumbar computed tomography (CT) imaging, as detailed below. Exclusion criteria included revision procedures, less than 1 year of follow-up, and lack of the specified CT imaging within the described parameters below.

All patients underwent direct lateral interbody fusion with polyetheretherketone (PEEK) implants (CoRoent, NuVasive Inc, San Diego, California), and posterior instrumentation (Vertebral body endplates at each level were carefully prepared using curettes and pituitary rongeurs to remove the overlying cartilage, with care to avoid compromising the subchondral bone. Each interbody cage was manually packed with bone morphogenetic protein2 (BMP-2) in collagen allograft (Infuse, Medtronic, Dublin, Ireland), with an average of $2.8 \mathrm{~mL}$ of allograft and $2.1 \mathrm{mg}$ of BMP-2 per level. Where patients also underwent a concurrent ALIF at the L5-S1 level, also using BMP-2 (Infuse, Medtronic, Dublin, Ireland) and PEEK implants (Brigade, NuVasive Inc), this was noted and included in post-hoc analyses but excluded from the LLIFspecific results and analyses. Interbody fusion was further reinforced by minimally invasive, percutaneously placed posterior instrumentation, performed either concurrently during the same procedure or in a staged fashion during the same admission for select cases (Reline/Precept, NuVasive Inc).

At 6 months and 1 year postoperatively, all patients underwent dedicated lumbar CT scans to evaluate progression of interbody fusion. Bony fusion was defined as a discrete, continuous bone bridge between adjacent endplates without lucency (Figure). All CT images were reviewed by a trained resident physician independent of the surgical team. Patients who did not undergo lumbar CT within these specified time points, or those whose imaging was incomplete (eg without coronal/sagittal refor- 
Table 1. Patient demographics, medical history, and surgical details. Age, body mass index, thyroid disease, and diabetes mellitus were not associated with increased risk of radiographic nonunion at 1 year. Number of operated levels and presence of concurrent L5-S1 anterior lumbar interbody fusion also did not affect nonunion rates.

\begin{tabular}{|c|c|c|c|c|}
\hline & Overall & $\begin{array}{l}\text { Patients with Complete } \\
\text { Bony Union at } 1 \mathbf{y}\end{array}$ & $\begin{array}{l}\text { Patients with Radiographic } \\
\text { Nonunion at } 1 \mathrm{y}\end{array}$ & $P$ \\
\hline Average age, y & 65 & 64 & 65 & .70 \\
\hline \multirow[t]{2}{*}{ Sex } & $76 \mathrm{M}$ & $59 \mathrm{M}$ & $17 \mathrm{M}$ & $\ldots$ \\
\hline & $90 \mathrm{~F}$ & $72 \mathrm{~F}$ & $18 \mathrm{~F}$ & $\ldots$ \\
\hline Average BMI, \% & 30.6 & 30.8 & 29.5 & .15 \\
\hline $\mathrm{DM}$ & 35 & 28 & 7 & .86 \\
\hline Thyroid disease & 18 & 13 & 5 & .46 \\
\hline Average no. of operated levels & 1.9 & 1.8 & 2.2 & .19 \\
\hline L5-S1 ALIF (total patients) & $103(166)$ & $83(131)$ & $20(35)$ & .50 \\
\hline
\end{tabular}

Abbreviations: ALIF, anterior lumbar interbody fusion; BMI, body mass index; DM, diabetes mellitus; F, female; M, male.

matting to adequately determine fusion), were excluded from the study and statistical analysis.

\section{Statistical Methods}

Fusion rates were calculated and analyzed with $\chi^{2}$ testing and analysis of variance. Subgroup analyses were then performed across each LLIF interbody level, L1-L2 to L4-L5, and also among varying construct lengths. Statistical significance was set at $P<.05$.

\section{RESULTS}

A total of 166 patients, including 312 interbody levels, were reviewed. Average age was 65 years (3186 years; Table 1). Average body mass index (BMI) was $39.6 \%$ (range: $19.4 \%-49.0 \%$ ). An average of 1.90 direct lateral levels were fused concurrently in each case. Seventy-nine patients $(48 \%)$ underwent 1 level LLIF fusion; 45 (27\%) underwent 2 levels; and $42(25 \%)$ underwent 3 or more levels (Table 2). Of note, 1 patient underwent 6 concurrent LLIF fusions for degenerative scoliosis with multilevel spondylolisthesis and foraminal stenosis. These interbodies went on to fusion at the 1-year followup.

At 6 months, $160(51 \%)$ levels showed bony union at the fused interbody. Of the remainder, $70 \%$ were fused at 1 year. At 1 year, the total fusion

Table 2. Lateral lumbar interbody fusion rates at 1 year by number of concurrent levels. Nonunion rates in patients undergoing multiple levels did not differ significantly from those who underwent 1 - or 2-level procedures $(P=.19)$.

\begin{tabular}{lcccc}
\hline $\begin{array}{l}\text { No. of } \\
\text { Levels } \\
\text { Operated }\end{array}$ & $\begin{array}{c}\text { No. of } \\
\text { Patients }\end{array}$ & $\begin{array}{c}\text { Complete } \\
\text { Bony Fusion } \\
\text { at 1 y } \\
\text { (All Levels) }\end{array}$ & $\begin{array}{c}\text { No } \\
\text { Bony Fusion } \\
\text { at 1 y } \\
\text { (Any Level) }\end{array}$ & $\begin{array}{c}\text { 1-y Fusion } \\
\text { Rate } \\
(\boldsymbol{P}=. \mathbf{1 9})\end{array}$ \\
\hline 1 & 79 & 65 & 14 & $82 \%$ \\
2 & 45 & 37 & 8 & $82 \%$ \\
$\geq 3$ & 42 & 29 & 13 & $69 \%$ \\
\hline
\end{tabular}

rate of this cohort was $85 \%$. Forty-six $(15 \%)$ interbodies did not show bony fusion by 1 year. Fusion rates from L1 to L4 were similar $(84 \%-87 \%$, $P=.97$; Table 3). The fusion rates in 1- and 2-level LLIF cases were the same $(82 \%)$ at 1 year. Cases involving 3 or more concurrent levels had a lower fusion rate at $69 \%$, but there was no statistically significant relationship between the number of concurrent LLIF levels operated upon and nonunion rate $(P=.19$; Table 2$)$. Patient demographics did not differ significantly between those who achieved full fusion at 1 year and those who did not: nonunion was not significantly associated with age $(P=.70)$, BMI $(P=.15)$, or medical comorbidities such as diabetes $(P=.86)$ or presence of thyroid disease $(P=.46$, Table 1$)$. Lastly, 103 patients $(62 \%)$ also underwent concurrent ALIF at L5-S1, and this also did not have a significant effect on the overall fusion rate $(P=.50$, Table 1$)$.

Complications requiring reoperation within the first year were rare. Two patients developed soft tissue infections that required irrigation and debridement within the first postoperative year. One patient underwent a partial removal of hardware for a painful screw, and 2 patients developed subsidence at their L5-S1 interbody from the ALIF procedure that led to posterior decompression procedures. Among the LLIF interbody cages placed, one patient developed symptomatic subsidence of the interbody cage and underwent spacer placement.

Table 3. Lateral lumbar interbody fusion rates at 1-year were similar across various lumbar levels $(P=.97)$.

\begin{tabular}{lcccc}
\hline Level & $\begin{array}{c}\text { Total } \\
\text { No. of } \\
\text { Levels }\end{array}$ & $\begin{array}{c}\text { Bony Fusion } \\
\text { at 1 y }\end{array}$ & $\begin{array}{c}\text { No } \\
\text { Bony Fusion } \\
\text { at 1 y }\end{array}$ & $\begin{array}{c}\text { 1-y Fusion } \\
\text { Rate }\end{array}$ \\
\hline L1-2 & 25 & 21 & 4 & $84 \%$ \\
L2-3 & 55 & 47 & 8 & $85 \%$ \\
L3-4 & 90 & 78 & 12 & $87 \%$ \\
L4-5 & 142 & 120 & 22 & $84 \%$ \\
\hline
\end{tabular}




\section{DISCUSSION}

LLIF has been described as a minimally invasive approach to address degenerative lumbar disease. As the technique has matured, excellent fusion rates at various time points have been reported in several single-institution cohorts. Fusion rates from $85 \%$ to $97 \%$ have been reported at 1 year. ${ }^{3-5,8}$ Initial studies, usually having a smaller cohort, were mainly 1-level or 2-level procedures. With the refinement and growing adaptation of the technique, larger studies have emerged. Recently, Nourian et $\mathrm{al}^{9}$ have described at average of 20 months postoperatively $92 \%$ fusion rate in 93 patients and 115 levels, which hitherto was the largest previous study of LLIF fusion.

The findings in this study corroborate the prior fusion rates reported. While a strict, conservative definition of radiographic bony union was intentionally selected, the $85 \%$ overall 1 -year fusion rate in this large-scale cohort lends strength to the efficacy of the direct lateral technique in achieving lumbar fusion. The 6-month fusion data also provide the strongest evidence thus far that LLIF patients may be radiographically healed much earlier than the 1-year milestone that is most commonly cited. This was first suggested by Malham et $a{ }^{4}{ }^{4}$ who in their series of 26 patients with 43 LLIF levels described $46 \%$ fusion at 6 months. In this investigation, slightly more than half of all levels operated on $(51 \%)$ were fused at 6 months. For the surgeon looking to either guide patient expectations preoperatively or their recovery postoperatively, these data provide an important reference point.

No statistical difference in fusion rates was detected between patients who received 1- or 2-level fusions and those who underwent additional concurrent levels. Nevertheless, 1-level and 2-level fusions appeared to have a nominally higher fusion rate at 1 year than those involving 3 or more levels (Table 2). As the present study was limited to 1-year postoperative imaging, it is unclear this finding is reflective of a true difference or if it is more reflective of longer recovery times associated with additional levels. With multiple additional interbody fusions, it is conceivable that one level may not easily fuse until the adjacent and surrounding levels achieve fusion first to eliminate any micromotion. Further longterm follow up data on these multi-level LLIF patients will likely continue to shed light on their recovery.
Current understandings of LLIF fusion must take into consideration the variety of graft options available to supplement fusion, which add an additional variable to the current literature. Berjano et $\mathrm{al}^{3}$ mixed autologous bone graft with either calcium triphosphate scaffold or ceramic synthetic graft (Attrax), and Rodgers et $\mathrm{al}^{5}$ used local vertebral body autograft, demineralized bone matrix, cancellous autograft, and iliac crest bone marrow aspirate. Iliac crest autograft was historically the most commonly used graft for interbody fusion and remains the gold standard. However, the donor-site morbidity associated with iliac crest harvest and the added procedural time are not trivial. As a result, many surgeons have transitioned to biologics to supplement and enhance fusion. For patients in this cohort, BMP-2 was chosen as the graft material of choice. Originally described for ALIF in the lumbar spine, studies have since reported use of BMP-2 through posterior, posterolateral, and transforaminal approaches with superior interbody fusion rates. ${ }^{10-13}$ In addition to its inherent osteoinductive properties, BMP-2 usage has been shown to reduce operative times and reoperation rates compared with traditional autografts. $^{14}$

There is a paucity of literature on how BMP-2 affects lumbar fusion after LLIF. BMP-2 usage in the LLIF approach was first described by Malham et $\mathrm{al}^{4}{ }^{4}$ later by Marchi et $\mathrm{al}^{8}$ in 2012 and Nouri et $\mathrm{al}^{15}$ in 2016, with excellent fusion rates in 1-2-level interbody fusions. ${ }^{4,8,11,15}$ In this large-scale cohort with a significant number of multilevel $(3+)$ fusions, the overall fusion rate is comparable to those reported by the prior studies, and it is also comparable to fusion rates with BMP-2 in the posterior lumbar interbody fusion (PLIF) and transforaminal lumbar interbody fusion (TLIF) literature $(83 \%-100 \%){ }^{4,8,15-17}$ Some have reported complications after BMP-2 usage in other techniques; these complications include antibody formation, postoperative radiculitis, osteolysis or subsidence, and seroma formation. ${ }^{18}$ This study focused on radiographic outcomes and reoperation rates, and in this cohort the use of BMP-2 to promote lumbar fusion appeared safe and efficacious. The 2 soft tissue infections in this cohort did not involve seroma or clear relationship to the BMP-2 graft. Only 1 case of LLIF-specific subsidence was noted, and only 2 cases of subsidence at adjacent L5-S1 ALIF were observed. This is far 
below the subsidence rates that have been reported across other interbody fusion approaches. ${ }^{10,19}$

One potentially deleterious outcome of subsidence or cage migration after posterior lumbar interbody fusion or transforaminal lumbar interbody fusion that may require reoperation has been migration of the cage into the spinal canal or neuroforamina. ${ }^{20}$ This was not seen in this cohort, and from a technical perspective, the direct lateral approach may offer some protection, as the anterior and posterior longitudinal ligaments are left intact and the neuroforamina are not directly compromised. Similarly, a concern of BMP-2 application through a transforaminal approach is that ectopic bone may then form to secondarily compromise the foramina. This is less of a risk through a direct lateral approach, as the graft is never directly applied near the foramina or other neural structures. No significant complications related to ectopic bone formation was noted in this study. As studies continue into the growing application of BMP-2 in lumbar surgery, these hypotheses warrant further testing and exploration.

A criticism of BMP-2, and biologics in general, has been of added cost, especially for index procedures. The same critique of cost, however, may be applied to symptomatic failed unions that require readmission or even revision, which often involves removal of hardware and/or extension of fusion beyond the original levels. Indeed, early costutility models have suggested that an effective primary fusion with BMP-2 may be less costly than that of a symptomatic pseudoarthrosis that necessitates repeated readmission/revision surgery. ${ }^{21}$ While formal comparisons between BMP-2 and other graft materials were beyond the scope of this study, the results shown in this cohort nevertheless reinforce the safe and reliable performance of BMP2 in LLIF.

The primary aim of this study was to evaluate radiographic bony union after LLIF. While pseudarthroses are a recognized complication of interbody fusion, they are not the only factor in patient recovery postoperatively. ${ }^{22}$ Patient-reported outcomes were outside of the scope of this investigation, which certainly bear importance for future study as long-term LLIF follow-up data begin to emerge, but as bony fusion is the primary surgical objective of any interbody fusion, this study provides an important reference point in evaluating the success of LLIF as a technique, an ongoing critical process that will and must continue.

\section{CONCLUSION}

LLIF is an efficacious and minimally invasive means of addressing lumbar pathology, and this large-scale cohort study further establishes reliable fusion rates at 1 year postoperatively. Significantly, approximately half of all operated levels showed bony union by 6 months postoperatively, an important reference point for guiding postoperative recovery and expectations. The addition of multiple LLIF levels beyond 1- or 2-level fusions did not have a significant impact on fusion rates, which supports the growing application of this maturing technique for more advanced deformities and pathology beyond its original applications.

\section{REFERENCES}

1. Ozgur BM, Aryan HE, Pimenta L, Taylor WR. Extreme lateral interbody fusion (XLIF): a novel surgical technique for anterior lumbar interbody fusion. Spine J. 2006;6(4):435-443. doi:10.1016/j.spinee.2005.08.012

2. Siu TLT, Najafi E, Lin K. A radiographic analysis of cage positioning in lateral transpsoas lumbar interbody fusion. $J$ Orthop. 2016;14(1):142-146. doi:10.1016/j.jor.2016.10.028

3. Berjano P, Langella F, Damilano M, et al. Fusion rate following extreme lateral lumbar interbody fusion. Eur Spine J. 2015;24(suppl 3):369-371. doi:10.1007/s00586-015-3929-7

4. Malham GM, Ellis NJ, Parker RM, Seex KA. Clinical outcome and fusion rates after the first 30 extreme lateral interbody fusions. ScientificWorldJournal. 2012;2012:246989246989. doi:10.1100/2012/246989

5. Rodgers WB, Gerber EJ, Patterson JR. Fusion after minimally disruptive anterior lumbar interbody fusion: analysis of extreme lateral interbody fusion by computed tomography. SAS J. 2010;4(2):63-66. doi:10.1016/j.esas.2010.03.001

6. Phan K, Rao PJ, Scherman DB, Dandie G, Mobbs RJ. Lateral lumbar interbody fusion for sagittal balance correction and spinal deformity. J Clin Neurosci. 2015;22(11):1714-1721. doi:10.1016/j.jocn.2015.03.050

7. Strom RG, Bae J, Mizutani J, Valone F 3rd, Ames CP, Deviren V. Lateral interbody fusion combined with open posterior surgery for adult spinal deformity. J Neurosurg Spine. 2016;25(6):697-705. doi:10.3171/2016.4.Spine16157

8. Marchi L, Abdala N, Oliveira L, Amaral R, Coutinho E, Pimenta L. Stand-alone lateral interbody fusion for the treatment of low-grade degenerative spondylolisthesis. ScientificWorldJournal. 2012;2012:456346-456346. doi:10.1100/2012/ 456346

9. Nourian AA, Harrington J, Pulido PA, McCauley JC, Bruffey JD, Eastlack RK. Fusion Rates of Lateral Lumbar Interbody Fusion Using Recombinant Human Bone Morphogenetic Protein-2. Global Spine J. 2019;9(4):398-402. doi:10. $1177 / 2192568218797097$

10. Mroz TE, Wang JC, Hashimoto R, Norvell DC. Complications related to osteobiologics use in spine surgery: a 
systematic review. Spine (Phila Pa 1976). 2010;35(9S):S86S104. doi:10.1097/BRS.0b013e3181d81ef2

11. Burkus JK, Gornet MF, Dickman CA, Zdeblick TA. Anterior lumbar interbody fusion using rhBMP-2 with tapered interbody cages. J Spinal Disord Tech. 2002;15(5):337-349. doi:10.1097/00024720-200210000-00001

12. Khan TR, Pearce KR, McAnany SJ, Peters CM, Gupta MC, Zebala LP. Comparison of transforaminal lumbar interbody fusion outcomes in patients receiving rhBMP-2 versus autograft. Spine J. 2018;18(3):439-446. doi:10.1016/j. spinee.2017.08.230

13. Hofstetter CP, Hofer AS, Levi AD. Exploratory metaanalysis on dose-related efficacy and morbidity of bone morphogenetic protein in spinal arthrodesis surgery. $J$ Neurosurg Spine. 2016;24(3):457-475. doi:10.3171/2015.4. Spine 141086

14. Zhang H, Wang F, Ding L, et al. A meta analysis of lumbar spinal fusion surgery using bone morphogenetic proteins and autologous iliac crest bone graft. PLoS One. 2014;9(6):e97049-e97049. doi:10.1371/journal.pone.0097049

15. Nouri A, Martin AR, Mikulis D, Fehlings MG. Magnetic resonance imaging assessment of degenerative cervical myelopathy: a review of structural changes and measurement techniques. Neurosurg Focus. 2016;40(6):E5. doi:10.3171/ 2016.3.Focus 1667

16. Even J, Eskander M, Kang J. Bone morphogenetic protein in spine surgery: current and future uses. J Am Acad Orthop Surg. 2012;20(9):547-552. doi:10.5435/jaaos-20-09-547

17. Boden SD, Kang J, Sandhu H, Heller JG. Use of recombinant human bone morphogenetic protein-2 to achieve posterolateral lumbar spine fusion in humans: a prospective, randomized clinical pilot trial: 2002 Volvo Award in clinical studies. Spine. 2002;27(23):2662-73. doi:10.1097/00007632200212010-00005

18. Tannoury CA, An HS. Complications with the use of bone morphogenetic protein 2 (BMP-2) in spine surgery. Spine J. 2014;14(3):552-559. doi:10.1016/j.spinee.2013.08.060

19. Vaidya R, Weir R, Sethi A, Meisterling S, Hakeos W, Wybo CD. Interbody fusion with allograft and rhBMP-2 leads to consistent fusion but early subsidence. J Bone Joint Surg Br. 2007;89-B(3):342-345. doi:10.1302/0301-620X.89B3.18270

20. Haid RW Jr, Branch CL Jr, Alexander JT, Burkus JK. Posterior lumbar interbody fusion using recombinant human bone morphogenetic protein type 2 with cylindrical interbody cages. Spine J. 2004;4(5):527-538; discussion 538-539. doi:10. 1016/j.spinee.2004.03.025

21. Jain A, Yeramaneni S, Kebaish KM, et al. Cost-utility analysis of rhBMP-2 use in adult spinal deformity surgery. Spine (Phila Pa 1976). 2020;45(14):1009-1015. doi:10.1097/brs. 0000000000003442

22. Hah R, Kang HP. Lateral and oblique lumbar interbody fusion-current concepts and a review of recent literature. Curr Rev Musculoskelet Med. 2019;12(3):305-310. doi:10.1007/ s12178-019-09562-6

Disclosures and COI: The authors declare that there are no conflicts of interests relating to this original scientific investigation. One author is a paid consultant for Nuvasive Inc, which was not involved in the design, analysis, or other part of this study. No external funding was received for this study that would represent a conflict of interest.

Corresponding Author: Hanci Zhang, MD, Duke University Medical Center, Box 104002, Durham, NC 27710. Phone: (919) 681-8111; Fax: (919) 681-7672; Email: hans.zhang@duke.edu.

Published 1 June 2021

This manuscript is generously published free of charge by ISASS, the International Society for the Advancement of Spine Surgery. Copyright $\odot 2021$ ISASS. To see more or order reprints or permissions, see http://ijssurgery.com. 